\title{
Author's Guidelines
}

\section{Paper submission}

Paper is a result of research or thought related to language and literature. Paper must consist of original, unpublished work not under consideration of publication elsewhere. Paper must be written in Arabic, English or Indonesian minimum of 10 pages and no longer than 15 pages.

\section{Paper format}

Paper format is quarto (A4), Cambria 11 and space 1 for Indonesian and English, traditional Arabic 14 and space 1 for Arabic in format (*.doc or *.docx).

Body of paper as follows:

a. Introduction elaborates background of study, research problem, purpose, significance, approach, and method.

b. Discussion is consist of sub topic

c. Closing is conclusion of result study

Paper subheading as follows:

First Level : : ALL CAPITAL LETTER, BOLD, LEFT JUSTIFY

Second Level : Capital Letter-small letter, Bold, Left Justify

Third Level $\quad$ : Capital Letter-small letter, Bold, Left Justify

Paper of research result must be consist of (a) Title; (b) Name of author without academic degree; (c) Abstract (maximum 200 words); (d) Key words; (e) Introduction without heading included review of related literature and purpose; (f) Method; (g) Discussion and finding; (h) Closing; (i) References and (j) Attachment.

Paper of thought result must be consist of (a) Title; (b) Name of author without academic degree; (c) Abstract (maximum 200 words); (d) Key words; (e) Introduction without heading; (f) Content; (h) Closing; and (i) References.

\section{Title}

The title is not more than 12 words. If the paper is a resume of thesis, the title of paper may not be as same as thesis title because paper is thesis core.

\section{Author}

Name of author is not espoused by academic title. Correspondence address and email must be written under author name. If author is studying, the name of university can be written down. If author more than one person, all of authors' name must be written include their correspondence address and email.

\section{Abstract and keywords}

Abstract is written in English and Indonesian not longer than 200 words included research problem, review of related literature, method, and conclusion. Keywords are not more than five words.

\section{In note}

References should be up to date and use in note. Foot note is used to explain certain term, example:

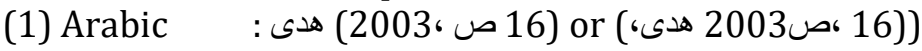

(2) English : : Littlejohn (2002, p. 19) or (Littlejohn, 2002, p. 19)

(3) Indonesian : Hamid (2014, h. 29) or (Hamid, 2014, h. 29) 


\section{Bibliography}

Literature does not need more books, but it more significant a little book related to topic.

Example of bibliography writing:

Littlejohn, S. W. (2002). Theories of human communication (7th ed.) California: Wadsworth.

(Last name, initial. (Publication year). Book title. Place of publication: Publisher.)

Thus, bibliography writing is accord with A.P.A (American Psychological Association) as follows:

1. Reference published periodically

The list of acquired reference put down a period of journal, magazine, newspaper, etc:

Kernis, M. H., Cornell, D. P., Sun, C., Berry, A., \& Harlow, T. (1993). There's more to self esteem than whether it is high or low: The importance of stability of self esteem. Journal of Personality and Social Psychology, 65, 1190-1204.

2. Reference published not periodically

The list of acquired reference put down a title and sub title of book, report, brochure, manual book, and audiovisual media:

O’Neil, J. M., \& Egan, J. (1992). Men's and woman's gender role journeys: Metaphor for healing, transition, and transformation. In B. R. Wainrib (Ed.), Gender issues accros the life cycle (pp. 107-123). New York: Springer.

Reference from journal (2 writers):

Klimoski, R., \& Palmer, S. (1993). The ADA and the hiring process in organizations. Consulting Psychology Journal: Practice and Research, 45, 10-36.

Reference from journal (more than 5 writers):

Wolchik, S. A., West, S. G., Sandler, I. N., Tein, J., Coatsworth, D., Lengua, L., et al. (2000). An experimental evaluation of theory-based mother and mother-child program for children of divorce. Journal of Consulting and Clinical Psychology, 68, 843-856.

Note: if the writer more than 6 writers in one reference, use et al.

Reference from journal in newspaper:

Zukerman, M., \& Kieffer. S. C. (in press). Race differences in face-ism: does facial prominence imply dominance? Journal of Personality and Social Psychology.

Reference from journal and newspaper:

Kandel, E. R., \& Squire, L. R. (2000, November 10). Neuroscience: Breaking down scienctific barriers to the study of brain and mind. Science, 290, 1113-1120.

Reference from article in newspaper with no writer:

The new health-care lexicon. (1993, August/September). Copy Editor, 4, 1-2.

Reference with no issue and no serial number:

Wolchik, S. A., West, S. G., Sandler, I. N., Tein, J., Coatsworth, D. (2000). An experimental evaluation of theory-based mother and mother-child program for children of divorce. Journal of Consulting and Clinical Psychology, 58(1, Serial No. 231).

Reference from additional journal:

Wolchik, S. A., West, S. G., Sandler, I. N., Tein, J., Coatsworth, D. (2000). An experimental evaluation of theory-based mother and mother-child program for children of divorce. Journal of Consulting and Clinical Psychology, 24(Suppl. 2), 4-14

Reference from book:

Beck, C. A. J., \& Sales, B. D. (2001). Family mediation: Fact, myths, and future prospects. Washington, DC: American Psychology Association. 
Reference from third book and the name of writer by addition of Jr. (Junior):

Mitchell, T. R. \& Larson, J. R., Jr. (1987). People in organizations: An introduction to organizational behavior ( $3^{\text {rd }}$ ed.). New York: McGraw-Hill.

Reference from edited book:

Mitchell, T. R. \& Larson, J. R. (Eds.). (1987). People in organizations: An introduction to organizational behavior. New York: McGraw-Hill.

Reference from book with no writer and editor:

Merriam-Webster's collegiate dictionary (10 ${ }^{\text {th }}$ ed.). (1993). Springfield, MA: Meriam-Webster.

Reference from revised book:

Beck, C. A. J., Sales, B. D. (2001). Family mediation: Fact, myths, and future prospects (Rev. ed.). Washington, DC: American Psychology Association.

Reference from encyclopedia and dictionary:

Sadie, S. (Ed.). (1980). The new Grove dictionary of music and musicians (6 ${ }^{\text {th }}$ ed., Vols. 1-20). London: Macmillan.

Reference from English translated book:

Laplace, P. S. (1951). A philosophical essay on probabilities (F. W. Truscott \& F. L. Emory, Trans.). New York: Dover. (Original work published 1814).

Reference from brochure:

Research and Training Centre on Independent Living. (1993). Guidelines of reporting and writing about people with disabilities (4th ed.) [brochure]. Lawrance, KS: Author.

Reference from audiovisual media:

Scorsese, M. (Prosedure), \& Lonergan, K. (Writer/Director). (2001). You can count on me [Motion picture]. United States: Paramount Pictures.

Reference from recorded voice:

Costa, P. T., Jr. (Speaker). (1988). Personality, continuity, and changes of adult life (Cassette Recording No. 207-433-88A-B). Washington, DC: American Psychological Association. 


\section{Pedoman Penulisan Artikel Jurnal LiNGUA}

1. Artikel yang Bapak/Ibu kirimkan kepada kami adalah hasil penelitian, hasil pemikiran, dan/atau hasil penelitian lapangan yang mengungkap dan menganalisis bahasa atau sastra.

2. Artikel asli bukan hasil plagiarisme dan belum pernah dimuat di jurnal/berkala ilmiah lainnya.

3. Artikel ditulis dengan Bahasa Arab, Inggris, atau Indonesia antara 10-15 halaman A4. Menggunakan font Cambria 11, spasi 1 (latin), font Traditional Arabic, 14, spasi 1 (Arab), atau sesuai template artikel yang telah disediakan (download di web ejournal LiNGUA). File disimpan menggunakan ekstensi *.doc atau *.docx.

4. Artikel harus ditulis dalam bentuk essay dengan 'subheading' system sebagai berikut:

LEVEL SATU : SEMUA HURUF BESAR, CETAK TEBAL, RATA KIRI

Level Dua : Huruf Besar-huruf kecil, Cetak Tebal, Rata kiri

Level Tiga $\quad$ : Huruf Besar-huruf kecil, Cetak Tebal, Rata kiri

5. Judul tidak lebih dari 12 kata. Jika artikel merupakan ringkasan tesis, judul artikel tidak boleh sama dengan judul tesis, karena artikel merupakan inti dari tesis.

6. Nama penulis tidak disertai gelar akademik. Di bawahnya dicantumkan alamat lembaga tempat bekerja atau alamat korespondensi dan e-mail. Jika sedang melanjutkan studi, dapat pula disertakan alamat lembaga studinya. Jika penulis lebih dari satu orang, harus ditulis semuanya (termasuk alamat masing-masing).

7. Abstrak ditulis dengan Bahasa Inggris dan Bahasa Indonesia (ABSTRACT) maksimal 200 kata dalam satu paragraf, yang memuat: rumusan masalah, pendekatan/landasan teori dan cara penelitian, dan simpulan penelitian. Abstrak disertai kata kunci tidak lebih dari 5 kata.

8. Sistematika penulisan ditentukan sebagai berikut.

a. Bagian pengantar mencerminkan latar belakang, permasalahan, tujuan, manfaat, pendekatan,dan metode penelitian, tetapi penulisannya tidak seperti laporan penelitian atau makalah. Bagian pengantar ini diberi judul sesuai dengan pokok pikiran yang terkandung di dalam uraian.

b. Pembahasan, dapat terdiri atas beberapa subbahasan dan diberi subjudul sesuai dengan subbahasan, tanpa judul 'Pembahasan' di bagian awal.

c. Penutup adalah simpulan dari hasil penelitian (tanpa disertai saran-saran) dengan judul :Simpulan/Conclusion/خاتمةi

9. Referensi/Maraji' dianjurkan 'yang mutakhir', ditulis di dalam teks, footnote hanya untuk menjelaskan istilah khusus. Contoh
a. Arab

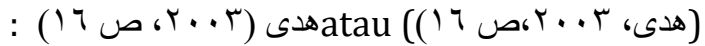
b. Inggris
: Littlejohn (2002, p. 19) atau (Littlejohn, 2002, p. 19)
c. Indonesia
: Hamid (2014, h. 29) atau (Hamid, 2014, h. 29)

10. Kepustakaan tidak perlu banyak tetapi berkaitan langsung dengan topik artikel. Untuk referensi berbahasa Arab tetap ditulis menggunakan latin/roman. Contoh penulisan kepustakaan:

Littlejohn, S. W. (2002). Theories of human communication (7th ed.) California: Wadsworth. [Nama belakang, Inisial. (tahun terbit). Judul buku. Tempat publikasi: Penerbit.]

11. Artikel hasil penelitian harus berisi (a) Judul; (b) Nama Penulis lengkap tanpa gelar; (c) Abstrak (maksimal 200 kata); (d) Kata Kunci; (e) Pendahuluan (Intoductio/Muqaddimah) tanpa heading yang termasuk tinjauan pustaka dan tujuan riset; (f) metode; (g) Diskusi dan temuan; (h) Penutup; (i) Daftar pustaka dan (j) lampiran, jika ada.

12. Artikel non-riset mencakup (a) Judul; (b) Nama Penulis lengkap tanpa gelar; (c) Abstrak (maksimal 200 kata); (d) Kata Kunci; (e) Pendahuluan (Introduction/Muqaddimah) tanpa heading; (f) Tubuh Tulisan; (g) Penutup; (h) Daftar pustaka. Penulisan Daftar Pustaka sesuai dengan A.P.A (American Psychological Association) 
13. Artikel dikirim melalui laman portal e-journal LiNGUA dengan alamat: http://ejournal.uinmalang.ac.id/index.php/humbud/index dengan mendaftar terlebih dahulu. 
